\title{
НИИ МОЛЕКУЛЯРНОЙ ЭЛЕКТРОНИКИ. БОЛЕЕ ПОЛУВЕКА НА ПЕРЕДНЕМ КРАЕ ОТЕЧЕСТВЕННОЙ МИКРОЭЛЕКТРОНИКИ
}

\section{MERI. MORE THAN SEMI-CENTURY AT THE FORWARD EDGE OF DOMESTIC MICROELECTRONICS}

Н.А.Шелепин, д.т.н., первый заместитель генерального директора НИИМЭ,

(ORCID: 0000-0002-7992-3611) / nchelepin@niime.ru

N.A.Shelepin, Doct. of Sc. (Technical), Deputy Director General of MERI

DOI: $10.22184 / 1993-8578.2020 .13 \cdot 5 \cdot 248.254$

Получено: 20.06.2020 г

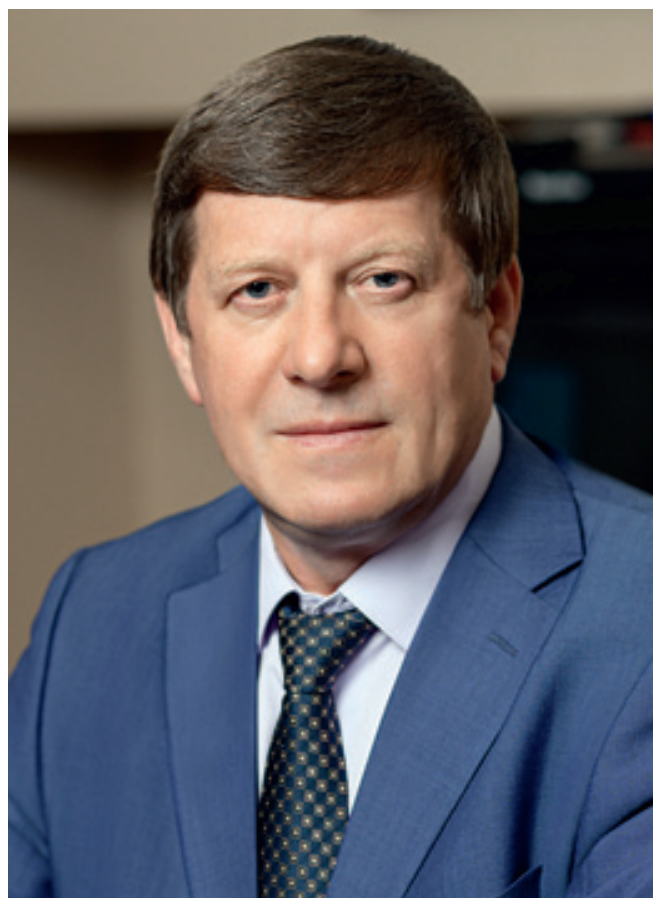

В научно-исследовательском институте молекулярной электроники уже более полувека успешно разрабатывают и внедряют в производство самые передовые в нашей стране технологии, интегральные схемы, СБИС, смарт-карты, радиационно-стойкие микросхемы для космоса, радиочастотные метки и чипы для паспортновизовых документов со средствами криптографической защиты информации. Полностью готовы к внедрению оригинальные удостоверения личности гражданина РФ, новые микросхемы для платежной системы "МИР", созданные совместно с ПАО "Микрон", накоплен богатый опыт взаимодействия с Национальной системой платежных карт. Уникальность разработок института состоит и в создании встроенного ПО для микросхем радиочастотной идентификации. Стартовал совместный проект с МТС о разработке модулей безопасности для шифрования данных, передаваемых по радиочастотным каналам для Интернета вещей. Об этих и многих других достижениях НИИМэ рассказывает первый заместитель генерального директора ниИмэ николай Алексеевич шелепин.

For more than half a century, the Molecular Electronics Research Institute has been successfully developing and implementing the most advanced technologies in our country, integrated circuits, VLSI, smart cards, radiation-resistant microcircuits for outer space, radio frequency tags and chips for passport and visa documents with cryptographic protection of information. The original identity cards of a citizen of the Russian Federation are fully ready for implementation, new microcircuits for the MIR payment system, created jointly with PJSC "Mikron", have accumulated rich experience of interaction with the National Payment Card System. The uniqueness of the Institute's developments lies in the creation of embedded software for RFID microcircuits. A joint project with MTS has started on the development of security modules for encrypting data transmitted over radio frequency channels for the Internet of Things. Nikolay Alekseevich Shelepin, Deputy Director General of NIIME, talks about these and many other achievements of MERI. 
Николай Алексеевич, расскажите, пожалуйста, что сделано в НИИМэ за последние пятнадцать лет его существования?

Научно-исследовательский институт молекулярной электроники (НИимэ) был образован в 1964 году, а уже через год при нем был организован опытный завод "Микрон". В советский период эти организации развивались параллельно, причем уникальность их симбиоза была необычна для того времени в целом по промышленности, но была применена в Зеленограде - две организации возглавлял один генеральный директор. В 90-е годы наступило акционирование предприятий, и они слились в одно, получившее название "НИимЭ и Микрон". Так оно функционировало до 2016 года, когда предприятие вновь было разделено на два: АО "НИИ молекулярной электроники" и ПАО "Микрон". Такая связка предприятий позволяла разделить сферы на научную и конструкторскую, которая проводится в НИИМЭ, и производственную, в "Микроне". Разработка конкретных изделий и микросхем в НИИМЭ проводилась с учетом производственных возможностей "Микрона", что обеспечило высокую оперативность освоения изделий в серийном и массовом производстве.

В 2006-2009 годах был реализован инвестиционный проект, в результате которого была создана новая фабрика и освоена технология уровня 0,18 мкм, благодаря чему к 2009 году мы уже получали первые образцы интегральных микросхем по лицензированной технологии уровня 0,18 мкм, a к 2012 году специалистами НИИМЭ была осуществлена разработка нескольких вариантов технологий данного уровня. В 2011-2012 годах был успешно осуществлен проект РОСНАНО по освоению технологического уровня 90 нм.

Реализация этих двух проектов позволила разрабатывать и изготавливать в России интегральные схемы со степенью интеграции до 200-300 млн транзисторов на чип. Следует заметить, что состояние технологий проектирования и изготовления микросхем регулярно подвергается аудиту большой экспертной группой, назначаемой Министерством промышленности и торговли Российской Федерации. Последний аудит состоялся в 2019 году и подтвердил возможности проектирования и изготовления микросхем с указанным технологическим уровнем, а также обеспечение работ в режиме foundry для отечественных дизайн-центров.

Подводя итоги развития последних 15 лет, коротко можно сказать следующее.

АО "НИимэ" - головная организация приоритетного технологического направления по электронным технологиям в соответствии с Распоряжением Правительства Российской Федерации. НИимЭ имеет практический опыт разработки и организации производств микросхем с технологическими уровнями 180-90 нм. В НИИмэ работают более 600 специалистов-разработчиков высокой квалификации, из которых три академика РАН, два члена-корреспондента РАН, более 50 докторов и кандидатов наук. Ученые института неоднократно награждались орденами и медалями, государственными премиями. Институт на постоянной основе сотрудничает с более чем 60 российскими и зарубежными научными центрами, техническими университетами и центрами проектирования.

Специалистами НИИМэ разработано около 10 базовых технологий уровня 180-90 нм, которые освоены в ПАО "Микрон" и на основе которых организована работа в режиме foundry с российскими дизайн-центрами, которыми осуществлена разработка более 130 типономиналов СБИС различного назначения.

В частности, нами разработаны технологии, библиотеки элементов и все правила проектирования микросхем, пригодных для применения в космических аппаратах, что привело, по данным компании "Российские космические системы", к переходу на использование отечественной элементной базы высокой степени интеграции. Если в 2012-2013 годах от 80\% применявшихся микросхем были импортными, то к 2017 году уже 75\% комплектующих электронной компонентной базы стали отечественными. Разработка технологий и средств проектирования обеспечивает соответствие микросхем для космоса всем требованиям, которые выставляются для подобных классов микросхем.

В НИИМЭ постоянно разрабатываются новые технологии. Сейчас одним из самых перспективных направлений нашей работы является разработка различных схем памяти: оперативной, однократно программируемой и перепрограммируемой. Фактически НИИМЭ сейчас является единственной в стране организацией, имеющей компетенции по разработке нескольких типов микросхем, в частности электрически перепрограммируемой памяти (FLASH), меток радиочастотной идентификации, смарт-карт.

Николай Алексеевич, расскажите о технологическом уровне разработок и производства. Какие перспективы открываются перед современными отечественными разработчиками чипов и производственниками? 
Рассмотрим вопрос шире. Сегодня в пяти компаниях мира освоены технологии с уровнем до 14 нм (Intel, Samsung, TSMC, GlobalFoundry, SMIC). Из них тайваньская TSMC и американская GlobalFoundry являются крупнейшими мировыми фабриками по изготовлению пластин для внешних разработчиков (foundry). И в целом никто не мешает отечественным разработчикам осуществлять коммерческие разработки и заказывать изготовление чипов на этих фабриках. Но здесь ключевым является слово "коммерческие". А с коммерческими проектами у нас пока очень проблематично. Основная причина в слабом спросе на отечественную ЭКБ. Но это отдельная большая проблема, которую пытается решить руководство отрасли.

Если рассматривать вопросы информационной безопасности государства, которая в современных условиях становится эквивалентной общей безопасности и даже независимости страны, то нам в России необходима новая фабрика, на которой можно было бы осваивать технологии указанного уровня. И практический опыт ученых и специалистов НИИМЭ будет обязательно востребован. Следует заметить, что в настоящее время НИИМэ является единственной в стране организацией, имеющей практический положительный опыт разработки и освоения в производстве современных технологий СБИС.

Рассматривая вопросы разработки и производства микросхем для космической аппаратуры, которыми мы не можем не заниматься в силу того, что Россия является космической державой, к сказанному выше необходимо добавить следующее. Как правило, технологический уровень микросхем для космических аппаратов (KA) на несколько поколений отстает от передового уровня коммерческих схем. Однако, по мере развития технологий разработчики СБИС для КА также переходят на всё меньшие проектные нормы. Так, если в 2012 году основной проектной нормой микросхем зарубежных компаний для КА было 0,25 и иногда 0,18 мкм, то сейчас мы видим реализацию для Европейского космического агентства консорциумом во главе c STMicroelectronics СБИС СнК с проектной нормой 28 нм. Российскими разработчиками создано несколько десятков типономиналов микросхем для КА на основе технологий и средств проектирования НИИМЭ уровня 0,18 мкм, начаты и успешно реализуются разработки по технологии 90 нм. Следует отметить такие новые разработки, как СО3У 16 и и реализованный на ее основе микромодуль СОЗУ 64M.
НИимэ является лидером в разработке чипов для паспортно-визовых документов, платежных и транспортных карт. Какой путь пришлось пройти, чтобы стать единственным отечественным разработчиком и производителем этих чипов?

Путь был непростым и тернистым. Условно можно сказать, что он состоял из четырех частей.

Во-первых, в части освоения новых технологий был осуществлен переход от уровня 1,0-0,8 мкм к уровню 0,18 мкм, то есть практически через пять поколений. Мы освоили технологию уровня 0,18 мкм не только "просто КМОП", а технологию со встроенной энергонезависимой перепрограммируемой памятью (ЭСППзу типа FLASH и EEPROM), которая значительно сложнее, в чем мы могли убедиться на ряде фабрик Китая, где освоили технологию КМОП, но не смогли запустить технологию КМОП + ЭСППЗУ.

Во-вторых, в части проектирования был осуществлен существенный качественный переход от проектирования относительно простых цифровых и аналоговых микросхем к сложнейшим системам на кристалле, которыми являются микросхемы для смарт-карт. Эти микросхемы содержат процессорное ядро, сопроцессор ускорения шифрования, цифровые блоки обеспечения протоколов обмена со считывающими системами, все виды схем памяти (ОЗУ, ПЗУ, ЭСППЗУ), аналоговые блоки обеспечения питания и радиочастотный блок бесконтактного интерфейса в соответствии с международным протоколом ISO 14443.

В-третьих, в части обеспечения функционального назначения, в микросхему "прошивается" встроенное программное обеспечение (ПО), которое является полноценной операционной системой (OC). И если на старте этих работ у нас было совершенно "нулевое" представление о том, что это такое, то к концу 2009 года мы уже изготавливали, тестировали и испытывали свои микросхемы с собственной встроенной ОС. Поэтому не без гордости могу сказать, что сегодня наш отдел по разработке встроенного ПО для смарт-карт является ведущим в стране в этой области.

В-четвертых, микросхемы для электронного паспорта и других идентификационных документов являются средствами криптографической защиты информации (СКЗИ). Соответственно для их разработки согласно законодательству необходимо иметь лицензии на данный вид деятельности и получать соответствующие сертификаты, что мы также успешно осуществляем. 
Естественно, НИИмЭ имеет лицензии на разработку шифровальных средств.

Однако здесь нельзя не вспомнить и негативный опыт государственно-частного партнерства. В октябре 2010 года было принято решение о введении в России "Универсальной электронной карты" (УЭК) гражданина Российской Федерации. Было создано акционерное общество "УэК", прошла волна постановлений на уровне правительства и создана нормативная база этого проекта, утверждены требования к универсальной электронной карте. Мы получили задание разработать программное обеспечение и сам чип электронной карты, но финансирование под эту государственную задачу почему-то не выделили. К маю 2011 года мы изготовили экспериментальные образцы со встроенным оригинальным ПО. При этом, кроме идентификационного приложения, карта должна была иметь и платежное, и транспортное приложения. Это была невероятно трудная задача, поскольку подобной по функционалу и сложности карты до того времени в мире создано не было. Для сертификации платежного приложения было заключено соглашение с Mastercard. Исследование средств безопасности микросхемы в части платежного приложения было проведено в аккредитованной лаборатории. Наша компания первой (и единственной до настоящего времени) в России прошла сертификацию ПО по стандартам безопасности платежной системы Mastercard.

В 2013 году была завершена сертификация всех приложений УэК, пройдена сертификация СКЗИ в ФСБ России, в 2014 году проведена сертификация на соответствие требованиям единой платежно-социальной системы УэК. Планы по производству были просто прекрасными. Планировалось выдать к концу 2014 года 79 млн шт., а до конца 2018 года - 99,5 млн карт гражданам Российской Федерации. Потом прогноз уменьшился до $12 \mathrm{mлн,} \mathrm{а} \mathrm{затем} \mathrm{государство} \mathrm{и} \mathrm{вовсе} \mathrm{свер-}$ нуло прогнозирование. Создание поликарбонатных карт было организовано в Зеленоградской фирме "Первый печатный двор", а практическая реализация достигла величины в 2013 году - 160 тыс. шт., в 2014 году - 164 тыс. шт., в 2015 году - 178 тыс. шт., в 2016 году - 30 тыс. шт. Итого за все время было выпущено лишь 532755 шт. И осталось еще полтора миллиона невостребован ${ }^{-}$ ных микросхем в незавершенном производстве "Микрона". Очевидно, что в этом проекте затраты на разработку не окупились и получилось, что вместо поддержки государство организовало убытки для ведущего микроэлектронного предприятия.
Новая эра по введению в оборот электронных удостоверений личности началась в конце 2014 года. Произошла активизация государственной подготовки по выпуску УЛГ - удостоверения личности гражданина РФ. Мы вновь начинаем разработку. Уже в июле 2015 года Правительству Российской Федерации были продемонстрированы первые опытные образцы, которые обеспечивали функционал удостоверения. В сентябре 2015 года прошло утверждение технических требований к интегральной микросхеме. Однако в начале 2016 года постановлением Правительства РФ все сроки были перенесены на 2018 год в связи с проведением выборов 2016 года. И все затихло.

В 2019 году были согласованы новые технические требования уже на совершенно новую микросхему с объемом энергонезависимой памяти 144 Кбайт вместо 72 Кбайт. Несмотря на все трудности и отсутствие финансирования со стороны государства, разработка в конце 2019 года была завершена, в начале 2020-го проведены проверка и сертификация этой микросхемы на соответствие требованиям СКЗИ, подготовлено все для промышленного производства.

Это наша новая разработка, рассчитанная на значительный государственный рынок, и мы очень надеемся, что в этот раз потребление нашей продукции будет обеспечено полностью, а граждане России начнут получать общегражданские паспорта или удостоверения личности с нашей микросхемой, изготавливаемой в ПАО "Микрон" и обеспечивающей высокую степень защиты данных в соответствии с российскими стандартами.

Полученный при разработке УэК опыт был весьма полезен при взаимодействии с созданной Национальной системой платежных карт (НСПК) и разработке новой микросхемы для платежных карт "МИР", где используются микросхемы нашей разработки и изготавливаемые в ПАО "Микрон". Мы уже имели практический опыт сертификации системы безопасности карты в зарубежной лаборатории, заключение которой принимается НСПК, и осуществили эту сертификацию на новой разработке. Однако производство микросхем для платежных карт практически не приносит прибыли "Микрону". Дело в том, что после объявления о создании в России НСПК стоимость платежных карт, поставляемых из-за рубежа в Россию, была снижена зарубежными производителями вдвое. Это к вопросу о добросовестной конкуренции и свободе рынка. Понятно, что компании, производственные мощности которых существенно выше, чем у "Микрона", могут выпускать аналогичную продукцию дешевле 
за счет большого рынка сбыта, чем они и воспользовались тогда.

Параллельно с разработкой микросхем для смарт-карт специалистами НИИмэ осуществлена разработка серии микросхем для различных систем радиочастотной идентификации. Практически все жители Москвы и Московской области держали эти изделия в руках в виде бесконтактных транспортных билетов. Это по-настоящему массовые изделия "Микрона", производство которых в некоторые месяцы доходило до 40 млн шт. в месяц. К настоящему времени их выпущено более 5 млрд шт. Следует отметить, что этот беспрецедентный пример разработки и серийного выпуска микроэлектронной продукции отмечен государством. За работу "Разработка и освоение серийного производства широкой номенклатуры микросхем для смарт-карт и радиочастотной идентификации на основе создания комплексных средств автоматизации проектирования и технологий изготовления современных интегральных схем со встроенной энергонезависимой памятью" коллектив авторов удостоен премии Правительства Российской Федерации в области науки и техники за 2015 год.

Николай Алексеевич, как в НИИмэ решаются проблемы кадрового голода специалистов в области микроэлектроники?

Вероятно, проблема кадрового голода у каких-то предприятий стоит очень остро. Естественно, в силу специфики деятельности, у нас нет проблем с кадрами рабочих специальностей. А наиболее эффективным решением подготовки молодых ученых и специалистов является работа с вузами, взращивание специалистов нашего профиля со студенческой доски. В основном, мы работаем с магистратурами базовых кафедр МИэТа и МФТИ. Это достаточно большое количество студентов, которые впоследствии становятся аспирантами и защищают диссертации по направлениям, которые ведет НИИМЭ. Как правило, они остаются у нас работать. Подпитка молодыми и очень амбициозными кадрами у нас происходит постоянно. Конечно, как и вся молодежь, они часто переоценивают свои силы и возможности, но наша уже сложившаяся научная школа позволяет воспитать их настоящими профессионалами своего дела и высококлассными специалистами, активно участвующими в решении наших очень непростых задач. В целом, можно считать, что обозначенной проблемы у нас практически нет.
Открыты ли вы частным инвесторам?

Заказы частных компаний в рамках тех технологий и производственных возможностей, которыми мы обладаем, нами выполняются, хотя в нашей стране этот рынок очень мал. Общее число заказов в области гражданской электроники у нас в стране очень небольшое. По нашей продукции - смарт-картам и микросхемам радиочастотной идентификации - рынок составляет, потенциально, миллиарды штук. Я об этом говорил выше. Принципиальным вопросом в области разработки микросхем является окупаемость и потенциал рынка сбыта подобной высокотехнологичной продукции. Для этого необходимо создание инфраструктуры, желательно централизованной, в регионах. Например, в области ЖКХ или автомобильной промышленности. Однако, например, регламентация установки на автомобили систем "ЭРА-ГЛОНАСС" не означает, что мы получим огромное количество заказов от производителей автомобилей, поскольку они вправе сами решать, с кем им выгодно сотрудничать и на основе каких элементов устанавливать электронные системы в поставляемые или производимые автомобили. Даже система "Платон" для большегруз ных автомобилей не обязательно должна быть создана на отечественных комплектующих. Последнее время отечественные микросхемы получают по некоторым направлениям преференции, введено понятие "отечественные микросхемы 1-го и 2-го уровней", но определяющим компонентом в плане реализации разработок является объем рынка. Это очень сложный вопрос: существует и большая инерция управления, и рыночная доступность, и тот факт, что если разработчики аппаратуры не связаны с обеспечением безопасности, то им проще даже не закупать комплектующие за границей, а сразу заказывать там целые блоки аппаратуры.

Примером такой технологии является блочная (а не компонентная) сборка телевизоров и другой бытовой техники. Они собираются из готовых блоков, поставляемых из-за границы. Переход к собственным разработкам на уровне компонентов - сложный путь, особенно если рынок уже захвачен иностранными мощностями, и быстро такие вопросы никогда не решаются. Одним из решений является создание собственных, внутренних, рынков для отечественной электронной промышленности, отечественных компонентов. Это отдельная, непростая задача, поскольку оценить потенциальные внутренние объемы подобных рынков непросто. Даже опираясь на данные ввозимых компонентов, можно сильно ошибиться по причине недостаточно достоверных данных о ввозимой электронной 
продукции вследствие неточностей в таможенной документации по их оформлению.

\section{Занимаются ли в НИИМЭ 3D-сборками?}

Да, занимаемся. Пока это не на уровне промышленных серийных изделий. Это интерпозеры и различные приемо-передатчики на их основе, компоновки нескольких компонентов на одну плату, комбинирование четырех микросхем памяти в одну микросборку и сборки класса 2,5D. За этими разработками большое будущее, но пока что отечественное производство недостаточно инвестировано для широкомасштабного конструирования и внедрения 3D-сборок. Расширится рынок - придут и инвестиции.

Как долго, по вашему мнению, просуществует кремниевая электроника?

Последние 10-20 лет идут непрерывные дискуссии по этому вопросу. Для силовой и СВЧ-электроники развиваются новые технологии на основе нитрида галлия на подложках карбида кремния. Есть идеи по выращиванию нитрида галлия на кремниевых подложках, что существенно удешевляет стоимость конечных изделий, и появляются перспективы развития силовой электроники на этой элементной базе. Она даже может оказаться дешевле кремниевой, поскольку для пропускания одних и тех же токов и приложения напряжений нитрид-галлиевым схемам требуется гораздо меньшие площади, чем кремниевым. Что касается альтернатив кремниевым транзисторам, то теоретических идей довольно много. Есть идеи построения триггеров, то есть цифровых электронных компонентов на молекулярном уровне. Можно вспомнить о нанотрубках, о которых активно публиковали работы около 10 лет назад, а примерно около 3-4 лет назад на конференции в Японии было объявлено, что почти никаких микросхем за все это время на основе нанотрубок создано не было. Суть больших интегральных схем состоит в том, что если участок этой схемы не функционирует, то он потребляет только токи утечки. Это главный принцип, по которому удалось получить микросхемы с сотнями миллионов и даже миллиардами транзисторов на одном чипе. Если же каждый вентиль хоть немного потребляет, мы не отведем выделяемое тепло от такой конструкции. Планы самых передовых компаний мира по созданию технологий уровня 3 и даже 2 нм до сих пор базируются на основе кремния. Лично я предполагаю, что даже после того, как будет создана, например, именно молекулярная электроника, то есть возможность изготовления логических элементов на основе соединения отдельных молекул, кремний останется базовым материалом для их размещения. Во-первых, вследствие технологического удобства и наработок. Во-вторых, вследствие необходимости создания интерфейсных частей к этой молекулярной логике, которые должны уметь "общаться" с существующими электронными системам. Следовательно, их необходимо будет делать из транзисторов.

\section{Какие технологии применяются на современном российском производстве?}

Если рассматривать слово технологии в широком смысле слова, то микроэлектронное производство и разработка используют множество самых наукоемких технологий. Циклы изготовления современных микросхем - это тысячи технологических операций, многие из которых повторяются в процессе производства, но, тем не менее, все они необходимы и часто безальтернативны. Все оборудование на современном производстве работает под компьютерным управлением, от нанесения прецизионных слоев диэлектриков, металлов, их травления, проведения литографии и т.д. Каждый такой процесс должен быть глубоко исследован, скажем, газофазное осаждение, магнетронное напыление, электрохимическое осаждение. В свое время создание технологии медной металлизации взамен алюминиевой на технологическом уровне 130 нм или применение металлического затвора вместо поликремниевого на уровне 45 нм явилось предметом гордости компании Intel. Уникальным оборудованием, сопровождающим производство, является электронная микроскопия, встроенная в конвейер по производству микросхем. Ранее это было возможно только в лабораторных условиях, а сейчас - в производстве. Это обеспечивает контроль качества выпускаемой продукции непосредственно в процессе его изготовления в соответствии с контроль-планом, что значительно снижает брак и улучшает выход готовой продукции, поскольку контролируется каждая технологическая операция - точность исполнения размеров, совмещений, ряда параметров осажденных диэлектрических слоев, все это проектируется заранее. Сейчас выход годных микросхем на несколько миллионов компонентов составляет $90 \%$.

Несколько слов в заключение о месте НИИМЭ в российской микро- и наноэлектронике

Уникальность НИИМЭ можно обозначить как составляющую следующих компетенций, которыми не обладают никакие другие организации: 
1. Высокая квалификация технологов и практический опыт разработки и внедрения передовых технологий изготовления микросхем;

2. Практический опыт и организация системы изготовления пластин для дизайн-центров в режиме foundry;

3. Практический опыт работ по экстракции моделей компонентов для разработанных технологий;

4. Уникальные компетенции по разработке микросхем для смарт-карт;

5. Уникальные компетенции по разработке встроенного ПО для смарт-карт;

6. Уникальные компетенции по разработке микросхем ЭспПзу.

Мы с большим оптимизмом смотрим в будущее, в котором все отчетливее просматривается цифровизация не только экономики, но и всех сфер жизни современного человека, и наш более чем полувековой путь - фундаментальная основа для будущей работы, выполнения всех поставленных задач на самом современном технологическом уровне. Мы готовы и к разработке новых чипов, и к массовому производству сложных и нужных технологических продуктов.

В настоящее время НИИМЭ имеет практический опыт разработки и запуска в производство изделий по самым передовым микроэлектронным технологиям в России. Разрабатываются уникальные микросхемы подобного класса - для смарт-карт и идентификационных документов. В России больше никто не обладает подобным опытом и возможностями. Вторая часть нашего ноу-хау - это разработка встроенного программного обеспечения и опыт создания микросхем радиочастотной идентификации. На этой базе мы сейчас в сотрудничестве с MTC начинаем разработку микросхем - модулей безопасности для Интернета вещей, с помощью которых шифруются данные, передаваемые по радиочастотным каналам.

Спасибо за интересную беседу.

\section{НОВЫЕ КНИГИ ИЗДАТЕЛЬСТВА «ТЕХНОСФЕРА»}

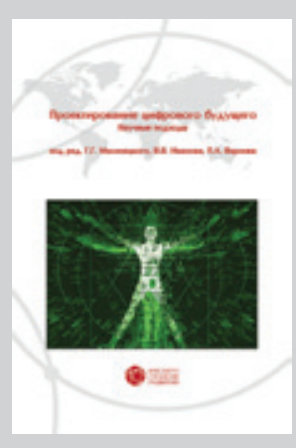

Цена 636 руб.
ПРОЕКТИРОВАНИЕ ЦИФРОВОГО БУДУЩЕГО. НАУЧНЫЕ ПОДХОДЫ

\section{КОЛЛЕКТИВНАЯ МОНОГРАФИЯ}

\author{
Под ред. Г. Г. Малинецкого, В. В. Иванова, П. А. Верника
}

Издание осуществлено при поддержке
АНО «Институт стратегий развития"

С междисциплинарных позиций рассматриваются вопросы формирования цифрового будущего в различных сферах - от философии, культуры, образования и конкретных технических проектов, возможность воплощения которых дают компьютерные технологии, до новых математических моделей и прогнозов.

Выделен ряд ключевых направлений, развитие которых может существенно повысить социально-экономическую эффективность программы цифровой экономики. 


\section{С ПОМОЩЬЮ НАНОМИКРОСКОПИИ УДАЛОСЬ ВПЕРВЫЕ УВИДЕТЬ МАГНИТНЫЕ СВОЙСТВА АВУМЕРНЫХ МАТЕРИАЛОВ}

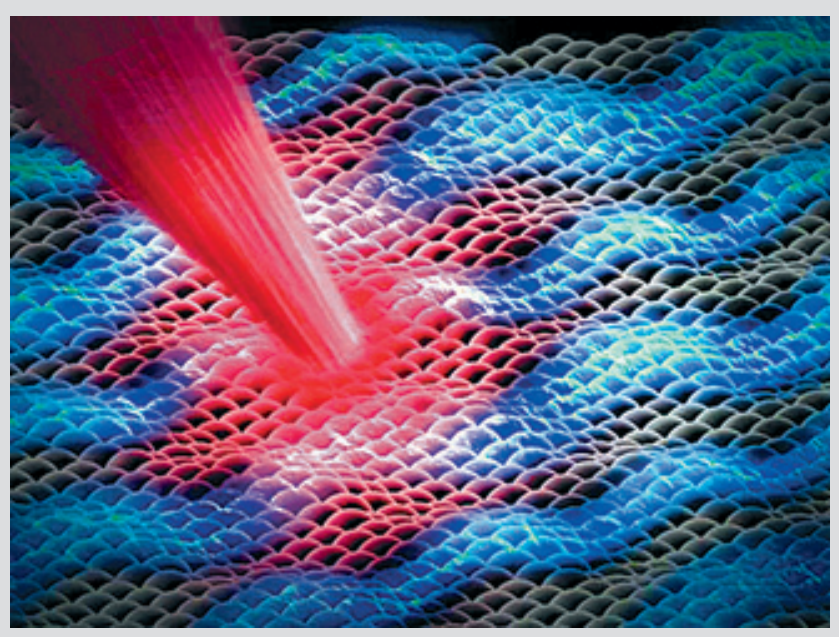

Новый наномикроскоп открывает двери новым материалам и технологиям.

Австралийские исследователи и их коллеги из России и Китая впервые наблюдали магнитные свойства ультратонких материалов с помощью новой техники микроскопии, открывающей дверь к открытию магнитных материалов с двумерностью больше двух (2D+).

Результаты, опубликованные в журнале Advanced Materials, показали, что современные методы, используемые для характеристики обычных (трехмерных) магнитов, не работают с двумерными материалами, такими как графен, из-за их чрезвычайно малого размера (как правило, толщиной в несколько атомов).

"До сих пор не было возможности точно сказать, насколько сильно был магнитным двумерный материал", - заявил Жан-Филипп Тетьен из Физической школы Мельбурнского университета и Центра квантовых вычислений и коммуникационных технологий.

Для решения этой проблемы команда под руководством профессора Ллойда Холленберга использовала широкоугольный микроскоп на азотных вакансиях. Этот инструмент был разработан совсем недавно, и его особенностью является высокая чувствительность и пространственное разрешение для измерения прочности двухмерных материалов.

"По сути, этот метод работает за счет того, что крошечные магнитные датчики (так называемые центры вакансий азота, представляющие собой атомные дефекты в алмазе) находятся настолько близко к двумерному материалу, что способны чувствовать его магнитное поле", - объяснил профессор Холленберг.

Для проверки этой методики ученые решили изучить вещество трииодид ванадия $\left(\mathrm{VI}_{3}\right)$, для которого уже установлено, что большие трехмерные фрагменты $\mathrm{VI}_{3}$ обладают сильным магнитным полем.

Используя новый микроскоп, ученые выяснили, что двумерные листы $\mathrm{Vl}_{3}$ также обладают магнитным полем, но оно примерно в два раза слабее, чем трехмерные образцы.
"Это было немного неожиданно, и в настоящее время мы пытаемся понять, почему намагничивание слабее в 2D, что будет важно для применения таких материалов в будущем", - отмечает доктор Жан-Филипп Тетьен.

Профессор Артем Оганов из Сколковского института науки и технологий в Москве (Сколтех) заявил, что полученные экспериментальные результаты могут привести к появлению новых технологий.

Всего несколько лет назад ученые сомневались, что двумерные магниты вообще возможны. С открытием двумерного ферромагнетика $\mathrm{Vl}_{3}$ возник новый захватывающий класс материалов. Новые классы материалов всегда означают появление новых технологий, как для изучения таких материалов, так и для использования их свойств.

Международный коллектив ученых планирует использовать наномикроскоп для изучения других двумерных магнитных материалов, а также более сложных структур, включая те, которые, как ожидается, будут играть ключевую роль в энергоэффективной электронике будущего.

По мamepuanam: phys.org

\section{ВАЛИДАЦИОННАЯ ЛАБОРАТОРИЯ АСЕПТИКА}
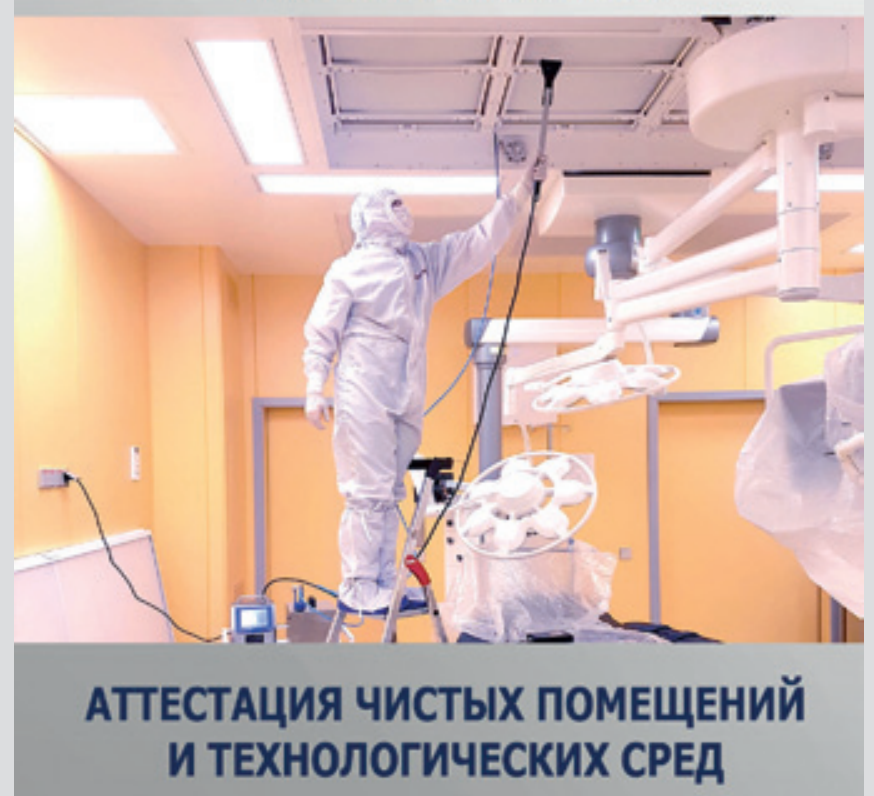

www.aseptica.biz

Ten.: (495) 249-02-42, (495) 585-88-15 E-mall: asep5858815@gmail.com 